\title{
CMEARTICLE \\ Primary care approach to managing acne
}

Aminath Shiwaza Moosa ${ }^{1}$, MBBS, MMed (FM), Joanne Hui Min $\underline{\text { Quah }}^{1,2}$, MMed, FCFP, Choon How $\underline{\text { How }}^{2,3}$, MMed, FCFP

\begin{abstract}
Roy, an 18-year-old polytechnic student, presented to your clinic with an uncomplicated upper respiratory tract infection and requested for a medical certificate to rest at home. His medical records showed that he had visited the clinic several times for minor ailments over the past few months. You also noticed that he had multiple pimples over his face. When prompted, he shared that he has an upcoming graduation ball in a few months' time and was worried about his appearance, particularly the pimples on his face.
\end{abstract}

\section{WHAT ARE PIMPLES?}

Pimples are inflamed comedones. They are red papules, pustules or nodules found most frequently on the face, neck and upper torso of adolescents and young adults. ${ }^{(1)}$ Pimples are part of acne vulgaris, which is a chronic inflammation of the pilosebaceous unit of our skin. Vulgaris is the Latin adjective for 'common', while acne vulgaris is likely the most common variant of acne.

Comedones arise from proliferation of cells lining the sebaceous duct (cornification) and an increase in sebum production (seborrhoea), primarily owing to the hypersensitivity of pilosebaceous units to circulating androgens (e.g. testosterone). Increased inflammation in comedones is a consequence of rise in sebum production, increase in colonisation with Cutibacterium acnes (previously called Propionibacterium acnes), and release of bacterial enzymes and sebaceous proinflammatory cytokines. ${ }^{(2)}$

\section{HOW RELEVANT IS THIS TO MY PRACTICE?}

Pimples, often accepted as part of puberty, can have profound social and psychological effects on adolescents or young adults when these affect their self-esteem, how they fit in with their peers or as they cope with new colleagues in their first workplaces.

In a local study conducted in Singapore, $88 \%$ of adolescents aged between 13 and 19 years reported that they had acne. ${ }^{3}$ Another study from National Skin Centre Singapore reported that $41 \%$ of adults seeking treatment had experienced acne since adolescence. Comedonal acne is more prevalent in adolescents, while cystic acne occurs more frequently in adults. ${ }^{(4)}$

\section{WHAT CAN I DO IN MY PRACTICE?}

Primary care doctors are well placed at the front line of healthcare to identify patients with moderate to severe acne, those at risk of scarring or those who are adversely affected socially and psychologically, when they present for any preventive or acute medical conditions. Informing patients of the availability of treatment modalities and stopping any preventable precipitating or perpetuating factors can be helpful even if the patients are not yet ready to start any clinical treatment.

\section{Important aspects in history taking History of aggravating and causative factors}

A detailed history can help to exclude systemic disorders (e.g. Cushing syndrome, androgen-secreting tumours) or medications (e.g. corticosteroids, anti-epileptics, isoniazide, rifampicin, lithium) as a cause of acne. Women should be asked regarding symptoms of hyperandrogenism (i.e. are menstrual periods regular? Is there hirsutism?). Variations in acne severity should be assessed, as they may be associated with hormonal swings in pregnancy and menopause. Occupational history may suggest exposure to oils and greases (chloracne); prolonged use of safety apparatus, such as well-fitting N95 masks, or motorcycle or industrial helmets, may result in friction or pressure on the skin (acne mechanica). The patient should be evaluated for use of occlusive cosmetics and skin products that are acnegenic (acne cosmetica), ${ }^{(5)}$ and their stress levels during an acne flare-up should be assessed. ${ }^{5,6}$

\section{History of previous treatment}

Patients often self-treat with over-the-counter medications and may have experienced treatment failure or relapse. It is important to explore the reasons for previous treatment failure or relapse. Patients should be asked what medications were taken, how they were taken (topical vs. systematic, dose, frequency, duration including maintenance and compliance), what adverse effects they experienced and what measures were taken to reduce the adverse effects.

\section{Psychosocial assessment \\ Patients affected by acne might manifest a range of psychological abnormalities and social dysfunction. This information may not be volunteered and will require prompting by the physician. Clues to identifying patients at high risk of psychological issues include}

SingHealth Polyclinics, ${ }^{2}$ SingHealth-Duke NUS Family Medicine Academic Clinical Programme, ${ }^{3} \mathrm{C}$ hangi General Hospital, Singapore

Correspondence: Dr Aminath Shiwaza Moosa, Associate Consultant, SingHealth Polyclinics, 167 Jalan Bukit Merah, Connection One, Tower 5, \#15-10, Singapore 150167. moosa.aminath.shiwaza@singhealth.com.sg 
poor eye contact, limited speech, angry or belligerent remarks, poor personal hygiene, and verbal self-depreciation. ${ }^{(6,7)}$ The physician should explicitly ask about low mood and/or anhedonia which, if positive, warrant further questioning on depression and suicidal ideation. The Cardiff Acne Disability Index is a patientadministered, easy five-question scale to use in routine clinical practice to assess a patient's psychosocial function. Its first two questions address the psychological and social consequences of acne in general; the third question seeks to assess the patient's self-image owing to acne over the back or chest; the fourth question enquires into his/her psychological state; and the last question asks for the patient's (subjective) assessment of his/her current acne severity. ${ }^{\left({ }^{8}\right)}$

\section{Clinical features of acne vulgaris}

Acne vulgaris is a polymorphic disease often characterised by simultaneous occurrence of comedones, papules, pustules, nodules and pseudocysts. Lesions develop from the sebaceous glands associated with hair follicles on the face, chest and upper back. Seborrhoea is frequently present. Box 1 lists the different types of lesions observed in acne and their description.

\section{Severity of acne}

The severity of the acne can be classified based on physical findings or the social and psychological impact on the individual. Based on the type of lesions and area affected, acne severity can be graded using the Comprehensive Acne Severity Scale (Table I). ${ }^{(9)}$ As discrepancies may occur with this classification based on the patient's quality of life, the patient's perceived severity of acne should be considered when grading its severity. Several skin conditions should be considered in the presence of acneiform eruptions. The differential diagnosis of acne is described in Table II.

\section{Treatment goals for acne vulgaris}

Acne should be actively managed, with goals to reduce comedonal and inflammatory lesions, improve psychosocial symptoms and prevent permanent scarring. Multiple treatment agents and formulations are available, and the treatment of acne depends on the patient's age and gender, disease severity, duration of the acne and tolerability. Table III details the management of acne according to disease severity. ${ }^{(10,11)}$ Myths associated with acne management need to be addressed when treating patients with acne. Table IV describes commonly encountered myths in the treatment of acne.

\section{Topical therapy}

Topical agents used for treatment of acne include creams, lotions and gels. The choice of preparation depends on the extent of area affected: creams and gels are preferred for small areas, and lotions are reserved for larger surfaces such as the upper torso. They should be applied to the entire site that is prone to acne rather than to the acne lesions alone. Most topical preparations can cause skin irritation, resulting in erythema, desquamation, dryness, stinging and pruritus, especially if applied excessively.
Box 1. Type and description of lesions observed in acne.

Non-inflamed

- Open comedones: blackhead

- Closed comedones: whitehead

Inflamed

- Superficial

- Papules (small, red bumps)

- Pustules (yellow'squeezable' spots)

- Deep

- Nodules (large painful red lumps)

- Pseudocysts (cyst-like large fluctuant nodules)

\section{Secondary lesions}

- Excoriations (picked or scratched spots)

- Erythematous macules (red marks from recently healed spots, best seen in fair skin)

- Pigmented macules (dark marks from old spots, mostly affecting those with dark skin)

- Scars of various types (ice pick scars, rolling scars, boxer scars, keloids and hypertrophic scars)

Table I. Comprehensive Acne Severity Scale.

\begin{tabular}{|ll|}
\hline Grade & Description \\
\hline 0-Clear & $\begin{array}{l}\text { No lesions to barely noticeable ones; very few } \\
\text { scattered comedones and papules }\end{array}$ \\
\hline 1 - Almost clear & $\begin{array}{l}\text { Hardly visible from 2.5 m away; few scattered } \\
\text { comedones and few small papules; very few } \\
\text { pustules, comedones and papules }\end{array}$ \\
\hline 2 - Mild & $\begin{array}{l}\text { Easily recognisable; less than half of the affected } \\
\text { area is involved; many comedones, papules and } \\
\text { pustules }\end{array}$ \\
\hline 3 - Moderate & $\begin{array}{l}\text { More than half of the affected area is involved; } \\
\text { numerous comedones, papules and pustules }\end{array}$ \\
\hline $4-$ Severe & $\begin{array}{l}\text { Entire area is involved; covered with } \\
\text { comedones, numerous pustules and papules, a } \\
\text { few nodules and cysts }\end{array}$ \\
\hline 5-Very severe & $\begin{array}{l}\text { Highly inflammatory acne covering the affected } \\
\text { area, nodules and cysts present }\end{array}$ \\
\hline
\end{tabular}

Reproduced with permission from Dr Jerry Tan.

Skin irritation can be improved by initiating the treatment at a low dose on alternate days, slowly titrating upward as required. A simple topical regime is recommended to improve compliance.

Benzoyl peroxide (BPO; $2.5 \%$ or $5 \%$ ) has comedolytic, antiinflammatory and bactericidal actions against Cutibacterium acnes ( $C$. acnes). It can be used alone or in combination with topical antibiotics or retinoids. The use of BPO in itself does not induce bacterial resistance, and it can be used in pregnancy. In addition to skin irritation, BPO can cause bleaching of hair or clothing.

Topical retinoids (tretinoin, adapalene) are Vitamin A derivatives that reduce microcomedones and mature comedones, promote desquamation of follicular epithelium and have an anti-inflammatory effect. Tretinoin may cause photosensitivity, and the use of sunscreens is advised. Clinical evidence does not support the belief that topical retinoids cause a flare-up in acne in the initial few weeks. ${ }^{(12)}$ Adapalene is better tolerated than 
Table II. Differential diagnosis of acne vulgaris.

\begin{tabular}{|c|c|c|c|c|}
\hline Diagnosis & Age of onset & Important factors & Location & Clinical features \\
\hline Rosacea & $30-50$ years & $\begin{array}{l}\text { Slow onset aggravated by cold, } \\
\text { alcohol, hot foods, stress; unknown } \\
\text { aetiology }\end{array}$ & Central face & $\begin{array}{l}\text { Erythema, telangiectasias, } \\
\text { papules/pustules; can present } \\
\text { with rhinophyma or chronic eye } \\
\text { inflammation }\end{array}$ \\
\hline $\begin{array}{l}\text { Perioral } \\
\text { dermatitis }\end{array}$ & $\begin{array}{l}\text { Primarily adult } \\
\text { women }\end{array}$ & $\begin{array}{l}\text { Sometimes associated with } \\
\text { prolonged use of high-potency } \\
\text { topical steroids }\end{array}$ & $\begin{array}{l}\text { Chin, perioral and nasolabial } \\
\text { folds }\end{array}$ & $\begin{array}{l}\text { Papules, pustules and erythema } \\
\text { confined to the chin and nasolabial } \\
\text { folds with sparing of the area } \\
\text { directly adjacent to the } \\
\text { vermilion border }\end{array}$ \\
\hline $\begin{array}{l}\text { Gram-negative } \\
\text { folliculitis }\end{array}$ & Any age & $\begin{array}{l}\text { Can be seen with long-term } \\
\text { antibiotic therapy }\end{array}$ & $\begin{array}{l}\text { (a) Nose and mouth areas } \\
\text { (common) } \\
\text { (b) Neck (uncommon) }\end{array}$ & $\begin{array}{l}\text { (a) Superficial pustules } \\
\text { (b) Large nodules }\end{array}$ \\
\hline Steroid acne & $\begin{array}{l}\text { Teenage to } \\
\text { adult years }\end{array}$ & $\begin{array}{l}\text { Associated with oral corticosteroid } \\
\text { therapy }\end{array}$ & Chest, upper arms and scalp & $\begin{array}{l}\text { Small, monomorphic papules, } \\
\text { pustules or closed comedones }\end{array}$ \\
\hline $\begin{array}{l}\text { Pityrosporum } \\
\text { folliculitis }\end{array}$ & $\begin{array}{l}\text { 20-30-year-old } \\
\text { male }\end{array}$ & $\begin{array}{l}\text { Increase during hot, humid weather } \\
\text { or increased sweating }\end{array}$ & $\begin{array}{l}\text { Upper trunk, back and } \\
\text { shoulders }\end{array}$ & $\begin{array}{l}\text { Absence of comedones and a } \\
\text { suspicious history, e.g. in a newly } \\
\text { conscripted national serviceman }\end{array}$ \\
\hline
\end{tabular}

Table III. Management of acne vulgaris.

\begin{tabular}{|c|c|c|c|}
\hline $\begin{array}{l}\text { Disease } \\
\text { severity }\end{array}$ & $\begin{array}{l}\text { Type of } \\
\text { therapy }\end{array}$ & Agent & Side effect/comment \\
\hline \multirow[t]{2}{*}{ Mild } & \multirow[t]{2}{*}{ Topical } & $\begin{array}{l}\text { For inflammatory lesions } \\
\text { - BPO }(2.5 \%, 5 \%) \\
\text { - Acne cream/lotion } \\
\text { (sulfur, SA and resorcinol) }\end{array}$ & $\begin{array}{l}\text { Burning, erythema, stinging and pruritis. } \\
\text { BPO can cause bleaching of hair and clothes. }\end{array}$ \\
\hline & & $\begin{array}{l}\text { For non-inflammatory lesions: topical retinoids (Vitamin } \\
\text { A-derived) } \\
\text { - Tretinoin }(0.025 \%-0.1 \%) \\
\text { - Adapalene } \\
\text { - Adapalene/BPO }\end{array}$ & $\begin{array}{l}\text { May produce irritant contact dermatitis and } \\
\text { photosensitivity (use of sunscreens recommended) }\end{array}$ \\
\hline \multirow[t]{4}{*}{ Moderate } & Topical & Same as mild acne & \\
\hline & \multirow[t]{3}{*}{$\begin{array}{l}\text { Systemic } \\
\text { (antibiotics) }\end{array}$} & $\begin{array}{l}\text { First line: } \\
\text { • Doxycycline } 100 \text { mg OD or BD } \\
\text { • Erythromycin } 500 \text { mg BD or } 250 \text { mg BD }\end{array}$ & $\begin{array}{l}\text { GIT upsets } \\
\text { Doxycycline can cause oesophagitis and } \\
\text { photosensitivity (take with a large glass of water } \\
\text { and use sun protection) }\end{array}$ \\
\hline & & $\begin{array}{l}\text { Second line: } \\
\text { • Minocycline } 100 \mathrm{mg} \mathrm{OM}\end{array}$ & $\begin{array}{l}\text { Expensive, vestibular toxicity, blue-grey cutaneous } \\
\text { pigmentation, lupus-like syndrome, hepatitis }\end{array}$ \\
\hline & & $\begin{array}{l}\text { Third line: } \\
\text { • Cotrimoxazole } 1 \text { tab BD or } 2 \text { tabs BD }\end{array}$ & Rashes, SJS/TEN, bone marrow suppression \\
\hline Severe & Systemic & $\begin{array}{l}\text { Oral isotretinoin: } 0.5-1.0 \mathrm{mg} / \mathrm{kg} \text { body weight/day } \\
(\max 120 \mathrm{mg} / \mathrm{kg})\end{array}$ & $\begin{array}{l}\text { Teratogenicity, plasma lipid abnormalities and } \\
\text { transaminitis, cheilitis }\end{array}$ \\
\hline $\begin{array}{l}\text { All disease } \\
\text { severity }\end{array}$ & $\begin{array}{l}\text { General } \\
\text { advice }\end{array}$ & $\begin{array}{l}\text { - Gentle soap-free pH-balanced cleanser or BPO cleanser } \\
\text { - Non-comedogenic or oil-free cosmetics } \\
\text { - Acne-specific moisturiser and sunscreen } \\
\text { - Low glycaemic index diet }\end{array}$ & \\
\hline
\end{tabular}

BD: twice daily; BPO: benzoyl peroxide; SA: salicylic acid; GIT: gastrointestinal tract; OD: every day; OM: every morning; SJS: Stevens-Johnson syndrome; TEN: toxic epidermal necrolysis

tretinoin, as it causes less skin irritation. ${ }^{(13)}$ Topical retinoids are recommended for maintenance after successful treatment of acne.

Acne creams and lotions are available over the counter and contain active ingredients such as sulfur, salicylic acid and resorcinol. These topicals induce a comedolytic effect by causing inter-corneocyte cell detachment; they improve skin texture and are recommended for inflamed comedones.

\section{Systemic therapy}

C. acnes has shown growing antibiotic resistance in Singapore. ${ }^{(3)}$ To reduce antibiotic resistance and increase efficacy, oral antibiotics should be used in combination with non-antibiotic topical agents. Oral antibiotics are indicated in the management of moderate to severe inflammatory acne owing to their anti-inflammatory effect as well as their action against $C$. acnes. Treatment for a 
Table IV. Myths and facts regarding treatment of acne.

\begin{tabular}{|c|c|}
\hline Myths & Facts \\
\hline Washing the face will reduce acne & $\begin{array}{l}\text { Excessive cleaning of the face increases dryness and may increase colonisation of } \\
\text { Cutibacterium acnes }\end{array}$ \\
\hline Antibiotic cream is the best treatment for acne & $\begin{array}{l}\text { Topical antibiotics will increase resistance to antibiotics, thereby affecting the efficacy of } \\
\text { treatment. Antiseptics such as benzoyl peroxide are preferred }\end{array}$ \\
\hline $\begin{array}{l}\text { Long-lasting cosmetics and sunscreens are } \\
\text { recommended for people with acne }\end{array}$ & Occlusive applications should be avoided as they may encourage comedone formation \\
\hline $\begin{array}{l}\text { Squeezing or popping 'ripe' pimples will speed } \\
\text { up healing }\end{array}$ & Squeezing can result in cystic lesions and scarring \\
\hline $\begin{array}{l}\text { Redness experienced after topical acne } \\
\text { treatment is always a sign of an allergy }\end{array}$ & $\begin{array}{l}\text { Skin irritations and solar sensitivity are known side-effects of many topicals. Temporary } \\
\text { cessation or lengthening of the frequency of application may be necessary after a review } \\
\text { assessment if it is not an allergic reaction }\end{array}$ \\
\hline $1-2$ pimples is/are not a big deal & $\begin{array}{l}\text { Important and stressful situations, such as a wedding photo shoot, may induce a pimple or } \\
\text { two. A supportive consultation and useful advice, e.g. use of a suitable makeup or concealer } \\
\text { may make a lot of difference to the affected person }\end{array}$ \\
\hline
\end{tabular}

minimum duration of 4-6 weeks is generally required to see a clinical improvement. The dosage is maintained until clearance, after which it is gradually decreased. Some patients require a low dose maintenance treatment for 1-2 months to prevent relapse. Oral antibiotic treatment should not exceed 3-4 months.

Doxycycline and erythromycin are recommended as first-line oral antibiotics. Erythromycin can be used to treat severe acne in pregnancy. Doxycycline is contraindicated in pregnancy and in children younger than eight years of age. Doxycycline should be taken with a large glass of water (to reduce oesophagitis and dyspepsia) and sun protection should be used (to alleviate photosensitivity).

Minocycline, advocated as the second-line oral antibiotic treatment for acne, is expensive, is associated with more central nervous system side effects, and has been linked to lupus and autoimmune hepatitis. Cotrimoxazole is recommended as the third-line treatment only when the patient is intolerant or unresponsive to other treatments. It is effective but carries a risk of serious adverse events (e.g. Stevens-Johnson syndrome/ toxic epidermal necrolysis, bone marrow suppression). It is also contraindicated in glucose-6-phosphate dehydrogenase deficiency.

Topical antibiotics may be considered only if the patient is unable to tolerate oral antibiotics and should be used in combination with other topical agents to avoid bacterial resistance. ${ }^{(14,15)}$

Further clinical options such as systemic isotretinoin or oral hormones may also be considered after further assessment if the initial therapies are ineffective or if the acne recurs after the treatment course has ended. Common dose-dependent adverse effects of isotretinoin include xerosis, cheilitis, acne flare-up, dry eyes, headache, and elevated lipid and hepatic enzyme levels. Pregnancy must be ruled out prior to starting therapy with oral isotretinoin, and female patients should be counselled regarding the risk of teratogenicity and appropriate contraceptive methods.

Combined oral contraceptives may be considered in female patients with moderate-to-severe papulopustular acne, signs of hyperandrogenism, need for effective contraception (e.g. during oral isotretinoin use), and as an adjuvant therapy to topical and systemic therapies.

WHEN SHOULD I REFER TO A SPECIALIST? Referral depends on treatment goals, severity of acne, and availability of formulary and equipment. Dermatologist referral is recommended in cases of severe, recalcitrant acne that fails to respond to first-line treatments. Severe scarring, psychological and/or physical distress or contraindications (e.g. allergies or intolerance) to the first lines of topicals and systemic therapy are also indications to refer for further assessments and early treatment. If clinical findings suggest underlying systemic disease, appropriate referrals to other specialty should be considered. The presence of a significant psychiatric comorbidity (depression, suicidal ideation) warrants prompt referral for counselling and, if required, psychiatric assessment.

\section{TAKE HOME MESSAGES}

1. Acne vulgaris is a common variant of acne that is commonly encountered by adolescents and young adults.

2. Although affected individuals may not visit a doctor for acne vulgaris, some may suffer from profound social and psychological effects and may be unaware that skin complications such as scars and keloids can be prevented or made less noticeable.

3. Acne vulgaris should be actively managed to prevent potential sequelae of acne, such as scarring, dyspigmentation and low self-esteem.

4. In addition to clinical findings, patients' perception of the severity of their acne should direct acne management.

5. Effective topical and systemic therapeutics for comedones and inflamed papulopustular acne can be offered by primary care physicians.

6. Antibiotics should be used only in combination with BPO and retinoids and for a maximum duration of four months to reduce the development of antibiotic resistance.

7. Referral to a dermatologist should be considered in severe, recalcitrant acne and in case of severe scarring, psychological distress or contraindications to conventional therapy. 
On examination, Roy was found to have moderate acne with numerous comedones, papules and pustules involving more than half of his face. He said that he had used acne creams (sulfur resorcinol cream) with slight improvement. He had decided to stop taking oral doxycycline owing to mild dyspepsia. He was not aware that he needed to take this oral medication after food. On further probing, you realised that Roy felt judged at polytechnic when he had bad acne flare-ups. His topical medication was changed to adapalene $0.1 \%$ cream every alternate night, to be applied for one week and then gradually increased to nightly use. Adequate use of sunscreen was emphasised. He was able to tolerate oral doxycycline 100 mg twice daily for six weeks, when taken after food and with a full glass of water. On follow-up six weeks later, his acne had improved, with a definite reduction in the number of acne lesions. You reduced his oral doxycycline to $100 \mathrm{mg}$ every day for another 4-8 weeks, and advised him to continue the adapalene cream for 3-6 months to prevent a relapse. Roy was looking forward to his graduation ball and was advised to use concealer to cover the remaining pimples for the event.

\section{REFERENCES}

1. Shen $Y$, Wang T, Zhou C, et al. Prevalence of acne vulgaris in Chinese adolescents and adults: a community-based study of 17,345 subjects in six cities. Acta Derm Venereol 2012; 92:40-4.

2. Thiboutot D, Gollnick H, Bettoli V, et al; Global Alliance to Improve Outcomes in Acne. New insights into the management of acne: an update from the Global Alliance to Improve Outcomes in Acne group. J Am Acad Dermatol 2009; 60(5 Suppl):S1-50.

3. Tan HH, Tan AW, Barkham T, Yan XY, Zhu M. Community-based study of acne vulgaris in adolescents in Singapore. Br J Dermatol 2007; 157:547-51.

4. Han XD, Oon HH, Goh CL. Epidemiology of post-adolescence acne and adolescence acne in Singapore: a 10-year retrospective and comparative study. J Eur Acad Dermatol Venereol 2016; 30:1790-3.

5. Whiting DA. Acne. West J Med 1979; 131:551-7.

6. Yosipovitch G, Tang M, Dawn AG, et al. Study of psychological stress, sebum production and acne vulgaris in adolescents. Acta Derm Venereol 2007; 87:135-9.

7. Fried RG, Wechsler A. Psychological problems in the acne patient. Dermatol Ther 2006; 19:237-40.

8. Motley RJ, Finlay AY. Practical use of a disability index in the routine management of acne. Clin Exp Dermatol 1992; 17:1-3.

9. Tan JK, Tang J, Fung K, et al. Development and validation of a comprehensive acne severity scale. J Cutan Med Surg 2007; 11:211-6.

10. Oon HH, Wong SN, Aw DCW, et al. Acne management guidelines by the Dermatological Society of Singapore. J Clin Aesthet Dermatol 2019; 12:34-50.

11. Oge' LK, Broussard A, Marshall MD. Acne vulgaris: diagnosis and treatment. Am Fam Physician 2019; 100:475-84.

12. Yentzer BA, McClain RW, Feldman SR. Do topical retinoids cause acne to "flare"? J Drugs Dermatol 2009; 8:799-801.

13. Greenspan A, Loesche C, Vendetti N, et al. Cumulative irritation comparison of adapalene gel and solution with 2 tazarotene gels and 3 tretinoin formulations. Cutis 2003; 72:76-81.

14. Gamble R, Dunn J, Dawson A, et al. Topical antimicrobial treatment of acne vulgaris: an evidence-based review. Am J Clin Dermatol 2012; 13:141-52.

15. Mills O Jr, Thornsberry C, Cardin CW, Smiles KA, Leyden JJ. Bacterial resistance and therapeutic outcome following three months of topical acne therapy with $2 \%$ erythromycin gel versus its vehicle. Acta Derm Venereol 2002; 82:260-5. 


\section{SINGAPORE MEDICAL COUNCIL CATEGORY 3B CME PROGRAMME} (Code SMJ 202111A)

1. Acne is common in adolescents and young adults owing to an increased level of circulating oestrogen.

2. Acne lesions develop from the sebaceous glands associated with hair follicles and are commonly located over the face, shoulder and upper torso area.

3. Pimples are accepted as part of puberty, usually resolve with age and do not result in complications or need active treatment.

4. Comedonal acne is more prevalent in adults, while cystic acne occurs more frequently in adolescents.

5. Drug-induced acne can be related to medications such as rifampicin, isoniazide and anti-epilepsy medications.

6. Blackheads form as a result of completely clogged follicles and dirty skin; thus, increased cleaning of the face will reduce blackheads and acne lesions.

7. Acne can be reduced by frequent washing of the face.

8. Eliciting occupational history is essential, as men who work as mechanics or engineers have an increased prevalence of acne, otherwise known as acne mechanica.

9. Patients with a high risk of psychological issues due to acne should be identified. Clues include poor eye contact, limited speech, angry or belligerent remarks, poor personal hygiene and verbal self-depreciation.

10. The Cardiff Acne Disability Index is a clinician-administered, five-question scale to use in routine clinical practice to assess a patient's psychosocial function.

11. Assessment of acne severity and acne management should be guided by only physical findings such as the type of lesions and the area affected.

12. Clinicians may grade acne as severe when the entire area is covered with comedones, pustules and papules, and a few nodules and cysts.

13. Steroid acne can be differentiated from acne vulgaris, where the former presents as monomorphic lesions and the latter as polymorphic lesions.

14. Superficial pustules or large nodules around the mouth or nose are suggestive of pityrosporum folliculitis.

15. Soap-free cleansers, oil-free cosmetics, sunscreens and topical creams have no role in severe acne, and clinicians should treat it with oral antibiotics only.

16. Cotrimoxazole is recommended only as a third-line treatment for acne, as it may be effective but can cause serious adverse events.

17. Clinicians should warn patients about the dose-dependent adverse effects of isotretinoin, such as dryness, skin peeling, dry eyes and headache upon initiation.

18. Skin irritation and redness from benzoyl peroxide cream used for acne treatment is an allergic reaction, and its use should be discontinued permanently.

19. Topical antibiotics have limited use in acne treatment. They may be an option for patients who are unable to tolerate oral antibiotics, and should be used in combination with other topical agents to avoid bacterial resistance.

20. Referral to a specialist is warranted if there is severe scarring, psychological distress and/or physical distress due to acne.

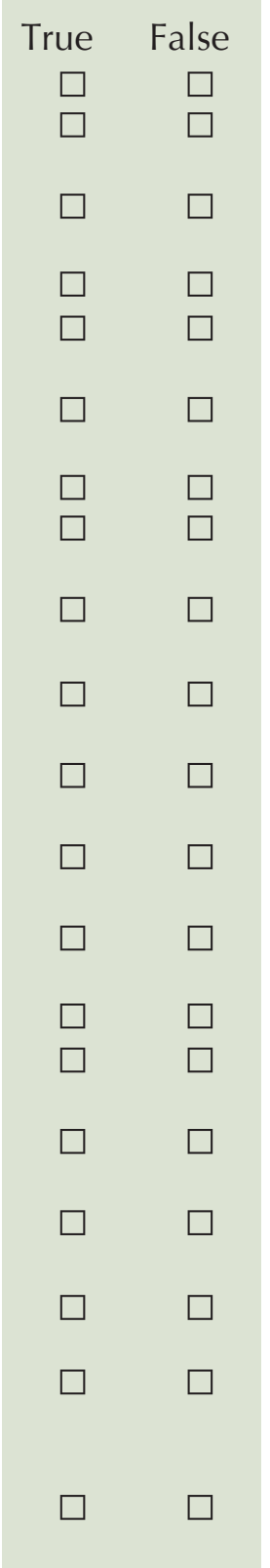

\section{Doctor's particulars:}

Name in full:

MCR no.:

Specialty:

Email:

\section{SUBMISSION INSTRUCTIONS}

Visit the SMJ website: http://www.smj.org.sg/current-issue and select the appropriate quiz. You will be redirected to the SMA login page.

For SMA member: (1) Log in with your username and password (if you do not know your password, please click on 'Forgot your password?'). (2) Select your answers for each quiz and click 'Submit'.

For non-SMA member: (1) Create an SMJ CME account or log in with your SMJ CME username and password (for returning users). (2) Make payment of SGD 21.40 (inclusive of $7 \%$ GST) via PayPal to access this month's quizzes. (3) Select your answers for each quiz and click 'Submit'.

RESULTS:

(1) Answers will be published online in the SMJ January 2022 issue. (2) The MCR numbers of successful candidates will be posted online at the SMJ website by 31 January 2022 (3) Passing mark is $60 \%$. No mark will be deducted for incorrect answers. (4) The SMJ editorial office will submit the list of successful candidates to the Singapore Medical Council. (5) One CME point is awarded for successful candidates. (6) SMC credits CME points according to the month of publication of the CME article (i.e. points awarded for a quiz published in the November 2021 issue will be credited for the month of November 2021, even if the deadline is in January 2022).

Deadline for submission (November 2021 SMJ 3B CME programme): 12 noon, 24 January 2022 